\title{
El suicidio como una forma de venganza.
}

Carta al Editor

Jesús Quintanilla-Osorio.

Servicios Estatales de Salud de Quintana Roo, Coordinación de Regulación Sanitaria, Chetumal, Quintana Roo, México.

De acuerdo con Sigmund Freud, el genial padre del sicoanálisis, en el acto del suicidio "no halla quizá la energía síquica suficiente para matarse quien, en primer lugar, no mata a la vez un objeto con el que se ha identificado, ni quien, en segundo lugar, no vuelve hacia sí, un deseo de muerte que iba dirigido a otras personas"(1), de forma tal, que el suicidio se convierte, al ser consumado, en un acto de venganza contra la persona que servía de objeto de identificación, y que puede ser el padre, la madre, el hijo, el esposo, etc.

Así, ese deseo de muerte contra otra persona que el suicida traslada a su propia experiencia quitándose la vida, es la manera de protestar, finalmente, contra un hecho consciente o inconsciente que le ha afectado profundamente.

Las motivaciones de un suicidio pueden ser desear liberarse de forma inconsciente, de las ataduras de una sociedad rígida, de una familia nuclear que no llena sus expectativas y donde no se ha trasladado el complejo de Edipo o de Electra a una independencia afectiva que permita determinar la propia elección del individuo, y de muchas otras formas(venganzas personales, etc.), pero siempre trasladando ese acto de atentar contra sí mismo, en una venganza póstuma. Es, en suma, su victoria contra quien necesitaba afectar. El suicidio representa así, la síntesis de una sociedad enferma que aliena al individuo y lo suprime, con reglas y normas morales muy convenencieras y ajustadas a los patrones de conducta que se desean y que, finalmente, constituyen un escape, nada recomendable, de la vida y sus complejidades, cuando existen otras opciones para realizar las aspiraciones personales.

Palabras clave: suicidio, depresión.

\section{REFERENCIA.}

1.- Freud S. Obras completas, T. XVIII. "Sobre la psicogenésis de un caso de homosexualidad femenina", 1920; Buenos Aires; Ed. Amorrortu; 1995.

Solicitud de sobretiros: Jesús Quintanilla-Osorio, Tlaxcalatongo 250 entre Carranza y San Salvador, Colonia V. Carranza, Chetumal, Quintana Roo, México.

E-mail: jesusin06_@hotmail.com

Recibido el 7/Mayo/2003. Aceptado para publicación el 30/Mayo/2003.

Este artículo está disponible en http://www.uady.mx/sitios/biomedic/revbiomed/pdf/rb031439.pdf

Vol.14/No.3/Julio-Septiembre, 2003 